\title{
Assessing Worry in Children: Psychometric Evaluation of the Indonesian Version of the Penn State Worry Questionnaire for Children (PSWQ-C)
}

\author{
Annastasia Ediati \\ Faculty of Psychology, Diponegoro University, Semarang, Indonesia \\ ediati.psi@gmail.com \\ Agustini Utari \\ Department of Pediatrics, Faculty of Medicine, Diponegoro University, \\ Semarang, Indonesia \\ agustiniutari@gmail.com
}

\begin{abstract}
The Penn State Worry Questionnaire for Children (PSWQ-C) is a well-known I4-items selfreport measure of worry in children and adolescents. Previous studies reported favorable psychometric properties in clinical and non-clinical samples, but recommendations given to use the full version or the shortened version of PSWQ-C are inconclusive. As a standardized measure of worry was not available in Indonesia prior to the study, the present study aims to evaluate the Indonesian version of PSWQ-C as a measure of worry on children and to assess worry in a large non-clinical sample of Indonesian children. We conducted forward-backward translation and applied the Indonesian translation of PSWQ-C on 653 children ( $3^{\text {rd }}$ to $5^{\text {th }}$ grades) from four state elementary schools in Semarang city. Furthermore, we also conducted comparison analysis across gender and grades. Principal component analysis resulted in two-factor structure of 14 items as well as a one-factor structure comprised II items. The reversed scoring items had poor psychometric qualities. The Indonesian version of I I-items PSWQ-C has satisfactory internal consistency $(\alpha=0.808)$. Young girls significantly scored higher than boys, but no significant differences were found across grades. The Indonesian version of the II-item PSWQ-C demonstrated favorable psychometric properties to be applied in the future studies. Intervention to prevent or reduce anxiety and depression in young children should consider gender and grades differences.
\end{abstract}

Keywords: PSWQ, worry, anxiety, children, Indonesia

Received 8 July2018/Accepted I4 January 2019 @JEHCP All rights reserved

\section{Introduction}

Worry is common among people across age. It has been known that worry associated with generalized anxiety disorder (GAD) in adults (Brown, Barlow, \& Liebowitz, 1994; Brown, Campbell, Lehman, Grisham, \& Mancill, 200I). A few studies reported similar findings in children and adolescents (Chorpita, Tracey, Brown, Collica, \& Barlow, 1997; Muris, Meesters, \& Gobel, 200I; Pestle, Chorpita, \& Schiffman, 2008). Persistent worry is defined 
as repeatedly thinking about the possibilities of threats, risks, uncertainties, and catastrophes in the future (Watkins, 2008). Worry can predict anxiety, both concurrently and prospectively (Hong, 2007; Watkins, 2008). The prevalence of worry among children is unknown. However, worry is an important feature of anxiety in young children as young as age five, and its prevalence and complexity tend to increase through middle childhood (Vasey, Crnic, \& Carter, 1994). Despite the reported similar studies from Western countries, studies on worry in Indonesian children is hardly conducted. One of the reason is the lack of validated instrument available to measure worry in children. The Penn State Worry Questionnaire for Children (PSWQ-C) was originated from the similar measure of worry on adults so called PSWQ (Meyer, Miller, Metzger, \& Borkovec, 1990). The PSWQ-C originally comprised I4 items to measure worry in children aged 8-12 (Chorpita et al., 1997; Muris et al., 200I; Pestle et al., 2008). Previous reports revealed that PSWQ-C followed one-factor structure when it was applied in a clinical sample (Muris et al., 200I), however, other studies reported a two-factor structure when it was applied in the clinical sample (Pestle et al., 2008). In Asian population, validation studies of PSWQ-C have been reported in Chinese college students and Korean children (Kang, Shin, \& Song, 2010; Zhong, Wang, $\mathrm{Li}, \& \mathrm{Liu}, 2009)$. Findings from the Korean study aligned with previous studies reporting the two-factor structure of PSWQ-C but the one-factor structure was preferred (Kang et al., 2010). A recent study in Romanian samples demonstrated the high construct validity of the PSWQ-C and the brief version of PSWQ-C. The study results also confirmed previous findings on gender differences in children, that girls reported a higher level of worry than boys, and clinical samples reported a higher level of worry than community samples due to worry trait (Păsărelu et al., 2016).

Previous studies revealed childhood anxiety and depression are important predictors of psychopathology in adulthood (Beesdo et al., 2007; Roza, Hofstra, Van Der Ende, \& Verhulst, 2003). When left untreated, these problems are likely to deteriorate (Harland, Reijneveld, Brugman, Verloove-Vanhorick, \& Verhulst, 2002). Therefore, early prevention of these disorders is of utmost importance. Initial screening of worry on children can help schools and parents to take an initial step in preventing the development of childhood anxiety and depression. However, by the time the paper is written, no standardized measures on worry are available in the Indonesian language. Consequently, data concerning 
worry in Indonesian children are lacking, in which the study was intended to fill this gap. This study is part of a larger study assessing worry, anxiety, and depression in Indonesian students and how schools, as well as parents, can contribute to the prevention program. The present study aims to evaluate the Indonesian version of PSWQ-C as a measure of worry on children and to assess worry in a large non-clinical sample of Indonesian children.

\section{Method}

Participants

The respondent comprised 653 elementary school students, aged 8-II years, grade 3-5, from four state elementary schools (350 boys; 293 girls) located in Semarang city. The researchers approached state elementary schools located in the slum area of Semarang assuming the highest incidence of worry among students. Two schools represent the low socio-economic status of the parents, whereas the other two schools represent the middle class in the society. We contacted the school principals and presented the study design to them as well as the classroom teachers of the $3^{\text {rd }}$ to $5^{\text {th }}$ grades for approval to participate in the study. In addition to information concerning the study, we also explained the benefits for schools and students by participating the study and also their rights to refuse or discontinue participation. We followed the common practice in our country to conduct a social study. Permission was given considering that the researcher or the research assistants were available during the children to fill in the questionnaire (PSWQ-C). We gave information about the study to the students prior to giving instruction to fill the measure. Data were collected in the classroom by the researchers and the research assistants. The classroom teachers were available in the class to accompany the students.

\section{Measure}

The PSWQ-C is 14-item self-report to measure worry in children and adolescents (aged 7 to 17 years) which originally developed in English (Chorpita et al., 1997; Pestle et al., 2008). Each item provides four options of response, ranged from never true, sometimes true, most times true, and Always true, which then scored between 0 to 3 (higher score indicates higher worry). Among these 14 items, three unfavorable questions were included in the PSWQ-C: "I do not really worry about things" (item 2), "I find it easy to stop worrying when I want" (item 7), 
and "I never worry about anything" (item 9). Previous studies reported poor performance of these unfavorable questions (Chorpita et al., 1997; Kang et al., 2010; Muris et al., 200I), but other studies suggested to keep these problematic items (Pestle et al., 2008; Zhong et al., 2009). In this study, we tested the original (I4 items) as well as the shortened (II items) versions and we applied the scoring procedure described in the original English version. The possible total scores obtained are 0-42 (for the original 14-items)and 0-33 (for the shortened I I-items) versions.

\section{Procedure}

Prior to the study, we obtained permission to conduct the study from our institution (Diponegoro University), the school principals as well as the classroom teachers of the participating schools. They received study information, explanation about the measures, the timing of the study, duration of answer the PSWQ-C, benefits of participating the study, and the rights of students and schools to refuse of discontinue their participation in the study. After data collection session was done, the students received small gifts to reward their participation in the study.

The validation of the Indonesian translation of PSWQ-C was done following the procedure to translate, adapt, and validate instrument or scale for use in a cross-cultural health care research (Sousa \& Rojjanasrirat, 20II). First, two independent translators translated the PSWQ-C English version into Bahasa Indonesia (the forward translation). Second, we discussed the results of the forward translation and reached agreement on the Indonesian translation of PSWQ-C. Third, we sent this translation (the initial Indonesian version of PSWQ-C) to other translators to translate the Indonesian version into English (the backward translation). Fourth, we compared the results of both forward and backward translations. A few differences in wording were discussed together between the translators and the researchers resulted in the final version of the Indonesian translation of PSWQ-C to be used in this study. 
Data analysis

In order to analyze the data, we conducted an exploratory factor analysis using the principal component analysis with varimax rotation. We explored the one or two component models and reported the best-fit model for this scale. The loading factor for each item was reported. Further, we calculated the item-total correlations for validity and the internal consistency using the Cronbach's alpha coefficient to evaluate the scale reliability. The independent t-test was used to investigate gender differences on PSWQ-C data and the one-way ANOVA was applied to compare data across grades. All statistical calculation in the study was performed using IBM SPSS Statistic version 23.0.

\section{Results}

The principal component analysis with varimax rotation method resulted in two-factor structure which explained $37.91 \%$ of total variance. Figure I showed the scree plot of the PSWQ-C Indonesian data with the eigenvalue higher than I. The 14 items loaded into two components where the reversed-scoring items (items 2, 7, and 9) grouped separately from the II-favorable items. Thus the two components separate the favorable and unfavorable items. The factor loadings of items following the one-factor and the two-factor structures were presented in Table I.

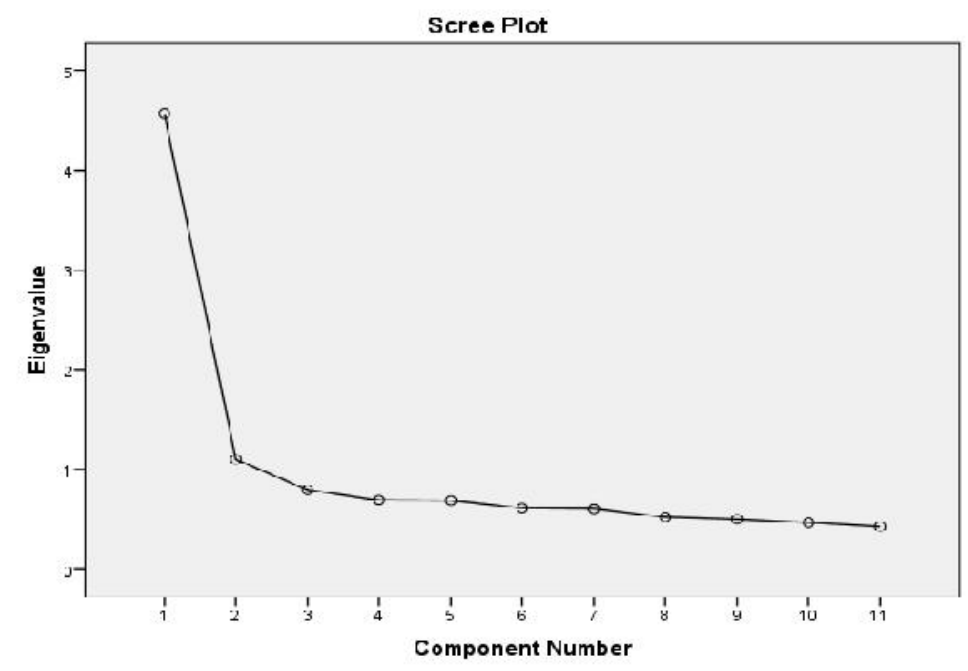

Figure I. The scree plot of the Indonesian PSWQ-C data 
Table I

Factor loadings of I 4 items PSWQ-C: The one-factor and two-factor structure

\begin{tabular}{lccc}
\hline \multirow{2}{*}{ PSWQ-C items } & & \multicolumn{2}{c}{2 factors } \\
\cline { 3 - 4 } & I factor & I & 2 \\
\hline Item I & $\mathbf{0 . 4 8 0}$ & $\mathbf{0 . 4 5 6}$ & -0.148 \\
Item 2* & -0.425 & -0.233 & $\mathbf{0 . 6 6 4}$ \\
Item 3 & $\mathbf{0 . 5 7 6}$ & $\mathbf{0 . 6 2 3}$ & 0.055 \\
Item 4 & $\mathbf{0 . 5 5 8}$ & $\mathbf{0 . 5 6 5}$ & -0.064 \\
Item 5 & $\mathbf{0 . 5 8 2}$ & $\mathbf{0 . 5 7 0}$ & -0.129 \\
Item 6 & $\mathbf{0 . 6 4 6}$ & $\mathbf{0 . 6 5 1}$ & -0.086 \\
Item 7* & -0.320 & -0.150 & $\mathbf{0 . 5 8}$ I \\
Item 8 & $\mathbf{0 . 5 5 3}$ & $\mathbf{0 . 5 2 9}$ & -0.162 \\
Item 9* & -0.152 & 0.085 & $\mathbf{0 . 7 6 5}$ \\
Item 10 & $\mathbf{0 . 5 9 9}$ & $\mathbf{0 . 6 0 3}$ & -0.08 I \\
Item II & $\mathbf{0 . 6 1 0}$ & $\mathbf{0 . 6 1 \text { I }}$ & -0.092 \\
Item I2 & $\mathbf{0 . 5 7 6}$ & $\mathbf{0 . 5 9 4}$ & -0.034 \\
Item I3 & $\mathbf{0 . 6 1 6}$ & $\mathbf{0 . 6 1 0}$ & -0.116 \\
Item I4 & $\mathbf{0 . 5 8 2}$ & $\mathbf{0 . 5 2 7}$ & -0.262 \\
\hline I & & &
\end{tabular}

Notes: Data were extracted using the principal component analysis with varimax rotation. *Unfavorable items in which reversed scoring were applied

Furthermore, Table 2 presents the item-total correlations and the internal consistency (measured by Cronbach's alpha) on both original and shortened version. The unfavorable items (items 2, 7, and 9) have poor item-total correlations compared to the II-favorable items. In the shortened version, all items have good item-total correlations. In overall, the Cronbach's alpha of the Indonesian version of PSWQ-C is increased if the three problematic items were excluded $\left(\alpha_{\text {original }}=0.665 ; \alpha_{\text {shortened }}=0.808\right)$. It can be concluded from data presented in Table 2 that the shortened version (II items) scale had better psychometric quality than the original version ( 14 items) scale. 
Table 2

The item-total correlations and internal consistency $(\alpha)$ of the PSWQ-C Indonesian data: The original (I 4-items) and shortened (I I-items) scales

\begin{tabular}{|c|c|c|c|c|}
\hline \multirow[b]{2}{*}{ PSWQ-C items } & \multicolumn{2}{|c|}{$\begin{array}{c}\text { Original } \\
(14 \text { items; } \alpha=0.665)\end{array}$} & \multicolumn{2}{|c|}{$\begin{array}{c}\text { Shortened } \\
\text { (I I items; } \alpha=0.808)\end{array}$} \\
\hline & $\begin{array}{l}\text { Corrected item- } \\
\text { total correlation }\end{array}$ & $\begin{array}{l}\text { Cronbach's } \alpha \\
\text { if item deleted }\end{array}$ & $\begin{array}{l}\text { Corrected } \\
\text { item-total } \\
\text { correlation }\end{array}$ & $\begin{array}{l}\text { Cronbach's } \alpha \\
\text { if item deleted }\end{array}$ \\
\hline Item I & 0.328 & 0.642 & 0.374 & 0.802 \\
\hline Item $2 *$ & -0.238 & 0.718 & - & - \\
\hline Item 3 & 0.456 & 0.622 & 0.477 & 0.792 \\
\hline Item 4 & 0.404 & 0.630 & 0.449 & 0.795 \\
\hline Item 5 & 0.424 & 0.626 & 0.475 & 0.792 \\
\hline Item 6 & 0.488 & 0.622 & 0.537 & 0.787 \\
\hline Item $7^{*}$ & -0.164 & $0.7 \mid 3$ & - & - \\
\hline Item 8 & 0.386 & 0.634 & 0.442 & 0.795 \\
\hline Item 9* & -0.009 & 0.695 & - & - \\
\hline Item 10 & 0.437 & 0.626 & 0.485 & 0.791 \\
\hline Item II & 0.444 & 0.626 & 0.495 & 0.790 \\
\hline Item 12 & 0.439 & 0.626 & 0.475 & 0.792 \\
\hline Item I 3 & 0.440 & 0.626 & 0.500 & 0.790 \\
\hline Item I4 & 0.385 & 0.632 & 0.462 & 0.794 \\
\hline
\end{tabular}

Notes: *Unfavorable items in which reversed scoring were applied

Comparison analysis across gender and grades were also conducted across PSWQ-C data obtained from this Indonesian samples. Table 3 presented the results of independent t-test and one-way ANOVA. It can be inferred from Table 3 that worry was significantly higher on girls compared to boys, whether it was assessed using the original (14-items) or the shortened version (I I items) of the Indonesian version of PSWQ-C. In view of worry across grades, no significant differences were found across students of $3^{\text {rd }}$ to $5^{\text {th }}$ grades. 
Table 3

Comparison analysis across gender and grades on the Indonesian data of the PSWQ-C

\begin{tabular}{|c|c|c|c|c|c|c|}
\hline \multirow{2}{*}{ Aspects } & \multicolumn{3}{|c|}{ Original (I4 items) version } & \multicolumn{3}{|c|}{ Shortened (II items) version } \\
\hline & $M$ & SD & $p$ & $M$ & SD & $p$ \\
\hline$N=653$ & 13.9 & 5.18 & & 7.68 & 5.4 & \\
\hline Gender $^{a}$ & & & $0.018^{*}$ & & & $0.024 *$ \\
\hline Girls $(n=360)$ & 14.45 & 5.36 & & 8.20 & 5.67 & \\
\hline Boys $(n=293)$ & 13.49 & 4.99 & & 7.25 & 5.14 & \\
\hline Grades $^{\mathrm{b}}$ & & & 0.335 & & & 0.613 \\
\hline $3^{\text {rd }}(n=214)$ & 14.33 & 5.21 & & 7.93 & 5.81 & \\
\hline $4^{\text {th }}(n=206)$ & 13.59 & 5.02 & & 7.41 & 5.29 & \\
\hline $5^{\text {th }}(n=233)$ & 13.83 & 5.27 & & 7.68 & 5.11 & \\
\hline
\end{tabular}

As the study was performed on a large non-clinical Indonesian sample, we reported the norms of the PSWQ-C Indonesian data presented as cumulative percentage and cut off points for 10 equal groups using the overall and gender-based data, measured by the original as well as the shortened versions of the PSWQ-C (see Table 4). 
Table 4

Cumulative percentage and percentile of the PSWQ-C Indonesian data

\begin{tabular}{|c|c|c|c|c|c|c|}
\hline \multirow{2}{*}{ Score } & \multicolumn{3}{|c|}{ Original (I4-item) PSWQ-C } & \multicolumn{3}{|c|}{ Shortened (I I-item) PSWQ-C } \\
\hline & $\mathrm{N}(653)$ & Boys (360) & Girls (293) & $\mathrm{N}(653)$ & Boys (360) & Girls (293) \\
\hline 0 & - & - & - & 7.4 & 8.3 & 6.1 \\
\hline I & - & - & - & 11.8 & 11.9 & 11.6 \\
\hline 2 & 0.2 & 0.3 & - & 18.5 & 20.0 & 16.7 \\
\hline 3 & 1.2 & $\mathrm{I} .4$ & 1.0 & 25.0 & 26.7 & 22.9 \\
\hline 4 & 1.8 & 2.5 & 2.0 & 34.8 & 35.8 & 33.4 \\
\hline 5 & 3.5 & 4.7 & 4.1 & 42.0 & 45.0 & 38.2 \\
\hline 6 & 6.1 & 7.8 & 6.8 & 48.1 & 52.2 & 43.0 \\
\hline 7 & 8.1 & 9.2 & 9.6 & 53.1 & 56.7 & 48.8 \\
\hline 8 & 11.2 & 12.5 & 18.4 & 59.6 & 62.2 & 56.3 \\
\hline 9 & 20.1 & 21.4 & 27.0 & 64.9 & 66.7 & 62.8 \\
\hline 10 & 29.2 & 31.1 & 34.1 & 70.1 & 71.9 & 67.9 \\
\hline II & 37.5 & 40.3 & 40.3 & 76.3 & 78.9 & 73.0 \\
\hline 12 & 43.8 & 46.7 & 47.4 & 80.7 & 83.9 & 76.8 \\
\hline 13 & 50.4 & 52.8 & 54.9 & 84.5 & 86.9 & 81.6 \\
\hline 14 & 57.6 & 59.7 & 62.8 & 88.2 & 90.6 & 85.3 \\
\hline 15 & 64.3 & 65.6 & 65.2 & 90.8 & 92.8 & 88.4 \\
\hline 16 & 68.8 & 71.7 & 74.1 & 92.6 & 95.3 & 89.4 \\
\hline 17 & 76.7 & 78.9 & 77.8 & 94.3 & 96.1 & 92.2 \\
\hline 18 & 80.9 & 83.3 & 81.6 & 95.9 & 96.7 & 94.9 \\
\hline 19 & 85.1 & 88.1 & 87.4 & 97.5 & 98.6 & 96.2 \\
\hline 20 & 89.1 & 90.6 & 88.7 & 98.5 & 99.4 & 97.3 \\
\hline 21 & 91.6 & 93.9 & 91.1 & 99.2 & 99.7 & 98.6 \\
\hline 22 & 93.9 & 96.1 & 93.9 & 99.5 & 99.7 & 99.3 \\
\hline 23 & 96.2 & 98.1 & 95.2 & 99.7 & 99.7 & 99.3 \\
\hline 24 & 96.9 & 98.3 & 95.9 & 100.0 & 99.7 & 99.7 \\
\hline 25 & 97.5 & 98.9 & 98.0 & & 99.7 & 99.7 \\
\hline 26 & 98.6 & 99.2 & 98.3 & & 100.0 & 100.0 \\
\hline 27 & 99.1 & 99.7 & 98.6 & & & \\
\hline 28 & 99.2 & 99.7 & 99.7 & & & \\
\hline 29 & 99.7 & 99.7 & 99.7 & & & \\
\hline 30 & 99.8 & 99.7 & 100.0 & & & \\
\hline 33 & 100.0 & 100.0 & & & & \\
\hline \multicolumn{7}{|c|}{ Percentile } \\
\hline 10 & 8 & 8 & 9 & I & I & I \\
\hline 20 & 9 & 9 & 10 & 3 & 2 & 3 \\
\hline 30 & 11 & 10 & 11 & 4 & 4 & 4 \\
\hline 40 & 12 & II & 12 & 5 & 5 & 6 \\
\hline 50 & 13 & 13 & 14 & 7 & 6 & 8 \\
\hline 60 & 15 & 15 & 15 & 9 & 8 & 9 \\
\hline 70 & 17 & 16 & 17 & 10 & 10 & 11 \\
\hline 80 & 18 & 18 & 19 & 12 & 12 & 13 \\
\hline 90 & 21 & 20 & 22 & 15 & 14 & 17 \\
\hline
\end{tabular}




\section{Discussion}

Worry in children is common. However, studies on worry in Indonesian children are scarce due to unavailability of reliable measure in Indonesian language (Bahasa Indonesia) prior to the study. This study aims to evaluate the Indonesian version of PSWQ-C as a measure of worry on children and to assess worry in a large non-clinical sample of Indonesian children. The principal component analysis that was performed on the 14 items of the PSWQ-C Indonesian data resulted in two-factor structure separating the II favorable items from the 3 unfavorable items. When one-factor structure was instructed, II items were loaded well into one component. The internal consistency of the shortened (II items) version of the Indonesian PSWQ-C is better than the original (I4 items) version. These findings aligned with previous study reported two-factor structure of the PSWQ-C (Pestle et al., 2008) and also with previous report on the one-factor structure of the PSWQ-C yielded the shortened (II items) version of PSWQ-C (Chorpita et al., 1997; Kang et al., 2010; Muris et al., 200I). Findings from our study suggest that the shortened (II items) Indonesian translation of the PSWQ-C demonstrated better psychometric properties than the original (I4 items) version because when the three problematic items were excluded, the reliability of the scale was increased significantly (from $\alpha=0.665$ to $\alpha=0.808$ ). Thus, we recommend the shortened version of the Indonesian translation of PSWQ-C to be used in the future studies to assess worry in Indonesian children.

In assessing worry in non-clinical Indonesian children, our study revealed gender differences in worry on children but not across grades. Worry was higher on young girls than young boys whether it was assessed using the original or shortened versions of the Indonesian PSWQ-C. This finding can be understood from the perspective of sex roles which indicates worry behavior are more accepted among girls than boys. Moreover, girls tend to have high levels of stress that lead them prone to worry (Zalta \& Chambless, 2008). Previous studies reported similar findings that girls scored higher than boys in the PSWQ-C (Chorpita et al., 1997; Esbjørn, Reinholdt-Dunne, Caspersen, Christensen, \& Chorpita, 20I3; Muris et al., 200I; Păsărelu et al., 2016; Pestle et al., 2008). In contrast, these findings did not support similar study from Asian sample which reported no significant gender differences in Korean children (Kang et al., 2010). In view of grades comparison, we assumed that students of the higher grades reported higher scores on worry than students of lower grades, as indicated 
by in the Korean samples (Kang et al., 2010). However, our findings suggested the opposite that worries among students of $3^{\text {rd }}$ to $5^{\text {th }}$ grades were not significantly differ. Unfortunately, the schools could not supply the age data to enable comparison analysis across age. These findings showed that worry is common in children and should not be undermined in the school-aged children. Parents and teachers often disregard worry in older children and pay more attention in helping younger children dealing with their worries. By doing so, parents and teacher might not realize their contribution in the development of anxiety and depression in the higher grades' students. As worries had been reported significantly higher on adolescents than younger children (Pestle et al., 2008), findings of the present study highlight the need to develop an anxiety and depression prevention program that also involve schools and parents.

\section{Conclusions}

The study showed that the shortened (II-items) version PSWQ-C Indonesia demonstrated a reliable measure that can be applied in future studies involving children in $3^{\text {rd }}$ to $5^{\text {th }}$ grades. Gender differences were found in worry on young Indonesian children. Worry is significantly higher on young girls than young boys participating in the study. However, worry does not differ across children in the $3^{\text {rd }}$ to $5^{\text {th }}$ grades as indicated in the study. It should be bear in mind that this study involved limited participants living in the capital city of the Central Java province. For future study it is expected to involve young participants from Sumatra, Kalimantan, Sulawesi, and the east Indonesia region which certainly will represent Indonesia. However, as no measure on children's worry was available prior the study, this study finding support the use of PSWQ-C Indonesia in future studies.

\section{Disclosure}

The authors declare no conflict of interests. 


\section{References}

Beesdo, K., Bittner, A., Pine, D. S., Stein, M. B., Höfler, M., Lieb, R., \& Wittchen, H.U. (2007). Incidence of social anxiety disorder and the consistent risk for secondary depression in the first three decades of life. Archives of General Psychiatry, 64(8), 903-912. http://doi.org/ I0.100 I/archpsyc.64.8.903

Brown, T. A., Barlow, D. H., \& Liebowitz, M. R. (1994). The empirical basis of generalized anxiety disorder. American Journal of Psychiatry, I 5 I (9), I272-1280.

Brown, T. A., Campbell, L. A., Lehman, C. L., Grisham, J. R., \& Mancill, R. B. (200I). Current and lifetime comorbidity of the DSM-IV anxiety and mood disorders in a large clinical sample. Journal of Abnormal Psychology, I I0(4), 585-599. http://doi.org/10.1037/002I$843 \times .110 .4 .585$

Chorpita, B. F., Tracey, S. A., Brown, T. A., Collica, T. J., \& Barlow, D. H. (1997). Assessment of worry in children and adolescents: An adaptation of the Penn State Worry Questionnaire. Behaviour Research and Therapy, 35(6), 569-58I. http://doi.org/I0.1016/S0005-7967(96)00I I6-7

Esbjørn, B. H., Reinholdt-Dunne, M. L., Caspersen, I. D., Christensen, L. B., \& Chorpita, B. F. (20I3). Penn State Worry Questionnaire: Findings from normative and clinical samples in Denmark. Journal of Psychopathology and Behavioral Assessment, 35(I), II3-122. http://doi.org/I0.1007/s 10862-0I2-9320-7

Harland, P., Reijneveld, S. a, Brugman, E., Verloove-Vanhorick, S. P., \& Verhulst, F. C. (2002). Family factors and life events as risk factors for behavioural and emotional problems in children. European Child \& Adolescent Psychiatry, II (4), I76-I84. http://doi.org//0.1007/s00787-002-0277-z

Hong, R. Y. (2007). Worry and rumination: differential associations with anxious and depressive symptoms and coping behavior. Behavior Research Therapy, 45, 277-290.

Kang, S. G., Shin, J. H., \& Song, S. W. (2010). Reliability and validity of the Korean version of the Penn State Worry Questionnaire in primary school children. Journal of Korean Medical Science, 25(8), I210-1216. http://doi.org/10.3346/jkms.2010.25.8.1210

Meyer, T. J., Miller, M. L., Metzger, R. L., \& Borkovec, T. D. (1990). Development and validation of the Penn State Worry Questionnaire. Behaviour Research and Therapy, 28(6), 487-495. http://doi.org/10.1016/0005-7967(90)90135-6

Muris, P., Meesters, C., \& Gobel, M. (200I). Reliability, validity, and normative data of the Penn State Worry Questionnaire in 8-12-yr-old children. Journal of Behavior Therapy and Experimental Psychiatry, 32(2), 63-72. http://doi.org/I0.1016/S0005-79I6(0I)00022-2

Păsărelu, C. R., Dobrean, A., Balazsi, R., Predescu, E., Șipos, R., \& Lupu, V. (20I6). The Penn State Worry Questionnaire for Children: Age, gender and clinical invariance. Child Psychiatry and Human Development, I-I I. http://doi.org/I 0.1007/s I0578-0I6-0663-2

Pestle, S. L., Chorpita, B. F., \& Schiffman, J. (2008). Psychometric properties of the Penn State Worry Questionnaire for children in a large clinical sample. Journal of Clinical Child 
and Adolescent Psychology, 37(2), 465-47I. http://doi.org/I0.1080/I537444I080I 955896

Roza, S. J., Hofstra, M. B., Van Der Ende, J., \& Verhulst, F. C. (2003). Stable prediction of mood and anxiety disorders based on behavioral and emotional problems in childhood: A 14-year follow-up during childhood, adolescence, and young adulthood. American Journal of Psychiatry, I60(12), 2116-2121. http://doi.org/I0.1176/appi.ajp.160.12.2116

Sousa, V. D., \& Rojjanasrirat, W. (20I I). Translation, adaptation, and validation of instruments or scales for use in cross-cultural health care research: A clear and userfriendly guideline. Journal of Evaluation in Clinical Practice, 17(2), 268-274. http://doi.org/I0.1 I I I/j.I365-2753.2010.01434.x

Vasey, M. W., Crnic, K. A., \& Carter, W. G. (1994). Worry in childhood: A developmental perspective. Cognitive Therapy and Research, 18, 529-549.

Watkins, E. (2008). Constructive and unconstructive repetitive thought. Psychological Bulletin, I34, I63-206.

Zalta, A. K., \& Chambless, D. L. (2008). Exploring sex differences in worry with a cognitive vulnerability model. Psychology of Women Quarterly, 32, 469-482

Zhong, J., Wang, C., Li, J., \& Liu, J. (2009). Penn State Worry Questionnaire: structure and psychometric properties of the Chinese version. Journal of Zhejiang University. Science B, I0(3), 21 I-218. http://doi.org/10.163 I/jzus.B0820I89 